\title{
Your financial future in six steps
}

With markets facing uncertainty Lloyd \& Whyte wanted to pass on some valuable tips to help you understand investments going forward:

1. Stick with it, markets go up and down.

Sadly your current pension and ISA will have taken a hit, however rest assured that history has taught us that markets recover. It may take two or even five years but Lloyd \& Whyte are certain that your investments will see growth again

2. Only invest what you can afford to invest. Lloyd \& Whyte's advice is to always look at your whole budget and invest what you can actually afford to live without. Now is a good time to re-evaluate your daily and monthly outgoings

3. Short term vs long term investment. Accessible savings account vs. shares? Consider not placing all of your eggs in one basket and keeping some of your money handy for short term emergencies

4. Review your portfolio regularly. Whilst it is good to stay invested, make sure the funds you are invested in are actually the best for your money and that how you are invested is still appropriate for your needs
5. Timing. Knowing when you need to access your money means you can take appropriate risks dependent on your short or long term needs

6. Tax. Use the allowances you are given. Pensions and ISAs provide tax efficiency, but there are other options available which can also maximise your finances.

Lloyd \& Whyte are available to help find the answers for your financial future. What matters to you, matters to them. You can call the team on 01823250750.

\section{Upskill your downtime}

In these difficult times, why not use a few hours of your downtime to develop your knowledge and skills and get up-date-date with the latest information and advice on the systems and software you use?

Carestream Dental is offering free, easily accessible webinars hosted by experts for all members of the dental team. Each 45-minute session will be live-streamed, providing existing users with an opportunity to enhance their understanding and capabilities ready for their return to practice.

The webinars will include David Claridge discussing intraoral scanning and Maik Gerullis exploring Carestream Dental imaging solutions, as well as a UK Application Specialist sharing hints and tips for CS R4+ software.

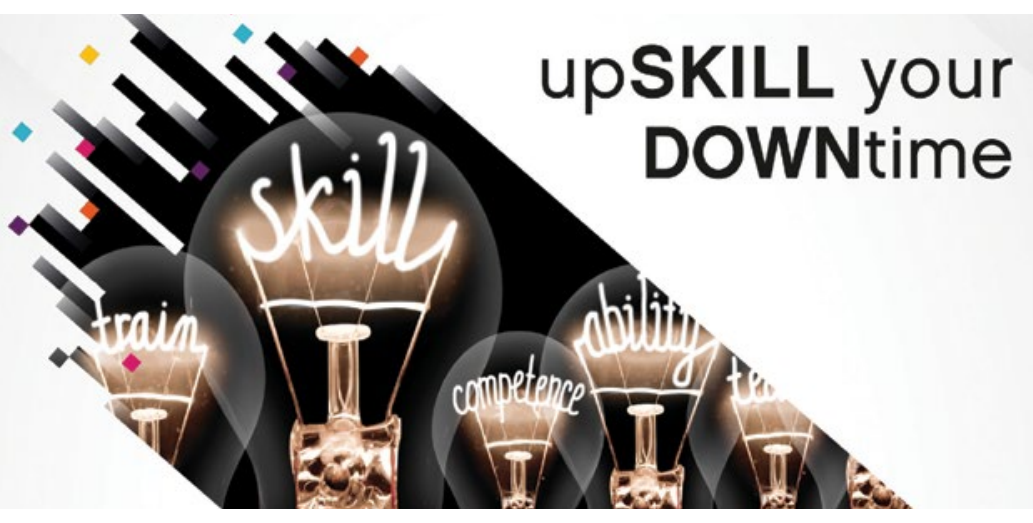

All Carestream Dental customers need to do is register for training through Eventbrite online and then you can bookmark relevant pages to check availability on the topics you are most interested in. Carestream Dental will be monitoring demand to tailor the training opportunities accordingly.
For CS R4+ training register at https://bit. ly/2y0jvmJ. For the series of CS Imaging/CS intraoral Scanning training register at http:// carestreamdentaluk.eventbrite.com/.

Got a topic you'd like covered? Let Carestream know by emailing gb-ddiukmarketing@csdental.com.

\section{Make phone calls directly from a patient's record}

Dentally's new feature means that outbound telephone calling is now fully integrated within its cloud patient management software, allowing you to make phone calls directly from the patient record.

During these unprecedented times while dental practices are working remotely, this new feature will mean that staff members can use their computer securely logged into Dentally to make all outbound calls. Returning messages or cancelling future appointments can all be done through the software, so staff won't incur costs for their phone usage at home.
As you would expect from the Dentally team it is simple to use. The calls that you make can use the practice telephone number as the caller ID or another number you have access to.

Once enabled by the Dentally team - a 'CALL' button will appear on all patient records. You click on the button which then brings up a drop down menu asking you to select which of the patients' phone numbers you wish to call (mobile or landline) and asking you to select the caller ID you wish to call from. You then place the call through the software on your computer. Once the call is completed you can hang up the call with the relevant button. During the call you can write any notes about the conversation you have had and click save. All of the details including the notes are then logged in the patient's correspondence tab in Dentally for future reference.

The new feature is available free of charge to all Dentally customers during the COVID-19 crisis as part of Dentally's commitment to supporting dentists in these difficult times.

If you would like to know more about this new product feature and other ways that Dentally is supporting its customers then simply email hello@dentally.co to talk to their team. 